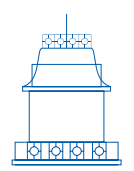

ARTÍCULOS

DE INVESTIGACIÓN

\title{
La religión sin Dios de Ernst Bloch como esbozo de una filosofía crítica*
}

\author{
Aníbal Pineda Canabal \\ Universidad Católica de Oriente, Rionegro, Colombia \\ E-mail: anibalpinedac71@gmail.com \\ Recibido: 15 de diciembre de 2019 | Aprobado: 3 de marzo de 2020 \\ https://doi.org/10.17533/udea.ef.n62a04
}

Resumen: Una de las características más originales de la filosofía de Ernst Bloch es la mezcla de elementos religiosos junto a una teoría de la emancipación en clave marxista. Su filosofía de la religión, sin embargo, se expresa de manera poco convencional y busca heredar los mejores productos del alma alemana, con el fin de superar el pesimismo de las filosofías del siglo XIX y revivir las luchas emancipadoras. El presente artículo explora las formas de expresión de este pensamiento en su filosofía de juventud a través de su alegato a favor de una "religión sin Dios" y contra todo ateísmo vulgar que elimine la experiencia de la interioridad humana. En este contexto, se presenta el concepto teológico de "Iglesia invisible" como el modo que encuentra Bloch de anclar la lucha anticapitalista y antimilitarista en un fuerte contenido simbólico que le sirviera de base. Se concluye que lo que está detrás de este proyecto es una crítica radical del sistema económico y la búsqueda de alternativas radicales a este.

Palabras claves: Ernst Bloch, religión, ateísmo, Kant, crítica, anticapitalismo

* Este artículo hace parte del proyecto de investigación Estudios críticos sobre el concepto de acontemporaneidad en el pensamiento de Ernst Bloch, adscrito al sistema de investigación y desarrollo de la Universidad Católica de Oriente y al grupo de investigación SER de la Facultad de Ciencias de la Educación.

\section{Cómo citar este artículo:}

Pineda Canabal, A. (2020). La religión sin Dios de Ernst Bloch como esbozo de una filosofía crítica. Estudios de Filosofía, 62, 57-74. https://doi.org/10.17533/udea.ef.n62a04 


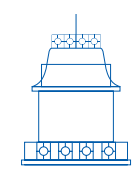

ARTÍCULOS

DE INVESTIGACIÓN

\section{Ernst Bloch's religion without God as an outline of critical philosophy}

Abstract: One of the most original features of Ernst Bloch's philosophy is the mixture of religious elements with an emancipation theory rooted in Marxism. However, his philosophy of religion is expressed in an unconventional way. It inherits the best products of the German soul in order to overcome the pessimism of the fin-de-siècle philosophies and revive the emancipatory struggles. This article explores the forms of expression of this thought in Bloch's early philosophy through the analysis of his claim for "religion without God", and against all vulgar atheism that abolishes the experience of human inwardness. In this context, the theological concept of the "invisible Church" is presented as Bloch's way of anchoring the anti-capitalist and anti-militarist struggle in a strong symbolic content that would serve as its base and reserve of energies. The paper concludes that, at the heart of Bloch's project, there is a radical critique of the economic system and a search for radical alternatives to it.

Keywords: Ernst Bloch, religion, atheism, Kant, critique, anticapitalism

\section{Aníbal Pineda Canabal}

Doctor en filosofía por la Universidad de Lovaina (UCLouvain). Ha publicado, entre otras cosas: En recuerdo de Ernst Bloch. Entrevista con Beat Dietschy (2018); La noción de democracia mística en Thomas Münzer, teólogo de la revolución (2015). 
"El filosofar ha caído en una situación completamente vergonzosa que en algún momento debe llegar a su fin" (Bloch, 1918, p. 245). La frase es lapidaria. El autor que la escribe deja rápidamente sentir al tiempo una mezcla singular de frustración y desesperanza. Los responsables de tal situación son enseguida señalados con el dedo: representan tanto a la filosofía universitaria de la época como al ambiente espiritual de la Alemania finisecular que, sin haber pasado por el cataclismo de una revolución burguesa, aceleraba su proceso de industrialización poniéndose, de un modo sui generis, en sintonía con los desarrollos de su tiempo. En el ritmo frenético que suponía para la sociedad de la época el descubrimiento de nuevas formas de vida y, en el contexto particular del ascenso de una nueva clase, junto a la pervivencia de estructuras socio-económicas profundamente anacrónicas, la filosofía parecía haber sucumbido a la dictadura del dato. La fidelidad minuciosa a los hechos externos, bandera del positivismo, pretendía explicar así cada parcela de la realidad, llegando incluso a deducir enteramente la conciencia a partir de reacciones químicas propias del cerebro y el sistema nervioso (Bloch, 1909). Al terreno pretendidamente neutral y objetivo de la ciencia parecía trasladarse de ese modo la actitud altanera de una burguesía que, por el momento, se sabía triunfante y segura de sus conquistas. Y puesto que nada podía sustraerse al primado de la objetividad, a nivel artístico triunfaba también la impresión como gobierno de la realidad externa sobre la psiquis. El impresionismo supuso, en este sentido, la victoria del color vivo que buscaba retratar tanto la frugalidad del paisaje, como la fugacidad de la luz y los instantes. Los pinceles dibujaron entonces una figura humana sin contornos, como hecha enteramente de acción, matiz entre los matices. A nivel del pensamiento, "la enorme presencia de un verdadero filósofo ha desaparecido hace tiempo" (Bloch, 1918, p. 246) y también "en los escritos académicos, el trabajo impresionista se consideraba a menudo como el único método que podía permitirse científicamente" (Bloch, 1908, p. 1) en la tarea de acceso y dominio tanto a lo natural como a lo histórico.

Sin embargo, el desconsuelo y la crítica implacable de su época que dejan ver las anteriores citaciones, distaban de ser una confesión a favor del pesimismo y de la inacción. Antes bien, al diagnóstico para nada halagüeño del propio tiempo, se unía la posibilidad de un cambio avizorado y creído posible en tanto que tarea todavía por realizar. Ernst Bloch llamará muy temprano a esta actitud tan suya "optimismo con un crespón de luto" (Bloch, 1923, p. 89). El oxímoron hace referencia, no tanto a la "espera de un desenlace sobre el que no cabe la menor duda" (Bloch, 2004, p. 146), cuanto a una invitación al viraje de toda pasividad contemplativa en esfuerzo y lucha. Se trata pues de un futuro posible que, aunque se anticipa bajo la forma de una utopía irrenunciable cuya consumación no está decidida por el edicto eterno de un Dios poderoso, todavía "existe como ciénaga" que solo puede "desecarse por medio del trabajo" (Bloch, 2004, p. 239), según la bella metáfora de El principio esperanza.

Así pues, junto a la visión descarnada del presente, numerosos testimonios apuntan a que el joven Ernst Bloch intentó superar los pensamientos derrotistas que sin cesar 
se ofrecían en el pensamiento de su época. Bloch soñó, pues, con una nueva época para el pensamiento alemán, una "nueva religión" que restaurara, como en los días de Goethe, Novalis y Schlegel, la profundidad del ejercicio filosófico y de la misma vida política, laboral y humana. Este sueño de juventud explica la búsqueda constante en toda su obra de fórmulas poéticas y performativas para expresar la necesidad de la movilización de contenidos subjetivos y simbólicos en el campo político. Ahora bien, la lucha contra toda absolutización del pesimismo y un anticapitalismo romántico que terminará desembocando en el marxismo, adquirirán en su juventud la forma particular de una mezcla de ateísmo y religión que constituirá uno de los signos más característicos que la posteridad retendrá de su obra. Nuestro objetivo en el presente estudio será mostrar la particular imbricación de estos dos elementos en su obra como una crítica a la sociedad industrial bajo la forma de una "gnosis revolucionaria" (Bloch, 1964, p. 347). Precisar las formas en que este pensamiento halla su expresión en los escritos tempranos de Bloch nos permitirá, acaso, según nuestra apuesta, responder a preguntas siempre actuales acerca de las condiciones subjetivas de los movimientos emancipadores.

\section{En favor de una nueva religión}

"La llamada de la vida (...) proviene de Nietzsche" (Bloch, 2019, p. 326). Si de lo que se trataba era de superar las filosofías pesimistas decimonónicas y todo pensamiento político derrotista, la filosofía de Bloch durante su juventud intentó, entre otras cosas, una recuperación del impulso fundamental dado por el pensamiento nietzscheano y su recuperación de lo dionisíaco. El alegato a favor de la vida resultaba ser, para nuestro filósofo, una lucha decidida contra las pretensiones de una verdad científica que había expulsado de su seno tanto al sujeto como a todo presentimiento del futuro. En cambio, bajo el estandarte de la reproducción acrítica de estados de hecho tenidos por la realidad sin más, la dictadura positivista del dato sirvió de justificación del statu quo propio del expansionismo imperialista. Nietzsche, junto a toda la tradición del humanismo ateo moderno, concebida por Bloch como una gran comunidad espiritual allende las épocas (Bloch, 1918), presiente algo todavía no consciente, y pone lo mejor en el futuro, en el hombre nuevo que Zaratustra anuncia (Bloch, 2019). El Dionisios de Nietzsche es, pues, el signo de lo que aún no ha llegado a ser, la metáfora que expresa una teleología de la inmanencia, el dios de algo todavía por venir en este mundo y no en ningún otro, y en favor de cuyo advenimiento se hace necesaria la lucha y no el desánimo.

Aparece así a los ojos de Bloch la necesidad de una nueva filosofía de la historia que aspire a la totalidad, más allá de los hechos observables que, sin conexión efectiva entre sí, dividen en compartimientos la realidad y aíslan las tendencias que la atraviesan. Sin embargo, la transformación deseada no puede operarse únicamente a nivel del pensamiento y aspira a una renovación misma de la cultura. Para lograrlo, Bloch parece 
lanzarse entonces a la búsqueda de contenidos performativos que permitan dar fácil anclaje a una nueva forma de pensamiento y de vida. Es así como encuentra en la vieja religión cristiana los elementos que le permitirán llenar de fórmulas poéticas y sugestivas, su defensa de una nueva mística política que, recogiendo los aspectos más granados de la cultura occidental europea, logre reactivar elementos presentes en la memoria cultural del pueblo.

Ya desde su primer texto conservado, Pensamientos sobre las cosas religiosas (Bloch, 1992), nuestro autor se pronuncia a favor de la recuperación del contenido afectivo de la palabra Dios, pero depurada de la corteza mitológica que tradicionalmente la ha envuelto. Sin embargo, al tiempo que su esfuerzo se aleja del positivismo, también busca apartarse de la crítica racional a la que la teología liberal había sometido al cristianismo'. Es en este sentido que Bloch sentencia ya en un texto de 1905: "lo que por principio determina la vida religiosa no se halla haciendo investigaciones históricas o dogmáticas sobre el origen de las religiones o sobre su legitimidad" (Bloch, 1992, p. 9). Ciertamente, la crítica ilustrada había echado por tierra el contenido metafísico del concepto Dios en tanto que inteligencia y voluntad separadas del mundo. El método histórico en la teología había también desvelado el camino de las grandes formulaciones dogmáticas del cristianismo (Harnack, 1961; Baur, 1867), principalmente durante sus primeros siglos, y había intentado compaginar ciencia y creencia de modo que estas no aparecieran más como ámbitos opuestos. Por su parte, el espejismo del concepto divino en tanto que pura construcción mental de la imaginación parecía haber sido definitivamente desenmascarado por la filosofía del siglo XIX. No así, en cambio, el contenido emocional que la palabra Dios mienta (der gefühlsmäßige Gehalt des Gottesbegriffes). En otras palabras, algo permanecía intacto para Bloch tras el brutal zamarreo al que la Ilustración y sus secuelas, tanto filosóficas como teológicas, habían sometido a la religión. Lo inamovible era el contenido desiderativo que funda el anhelo religioso, que se expresa en él y que sigue actuando aun ahora que el contenido abstracto y entitativo de la divinidad, ha perdido todo significado.

De lo que se trata entonces es de recoger un contenido humano que excede las formas socio-históricas de las religiones particulares puesto que pertenece a los "viejísimos territorios de la utopía" (Bloch, 2019, p. 75), cuyos senderos sin cesar y desde siempre ha recorrido el ser humano. Por eso, el desenlace de lo que Nietzsche llamó la "muerte de Dios" (Nietzsche, 2007), no podía ser según Bloch la instalación de

1 Hija legítima de la llustración, la teología liberal estaba convencida de que el cristianismo era, antes que nada, un fenómeno histórico que debía ser sometido al análisis riguroso de la crítica con el fin de descubrir la génesis y la evolución de sus doctrinas. El resultado consistió en una investigación radical sobre la fe que, si por un lado pretendía reconciliarla con los resultados de la ciencia, por otro, redujo al cristianismo a una especie de humanismo sincrético que mezcló lo griego y lo judío. En Bloch, es este sentido negativo de la teología liberal como "investigación puramente histórica de la Biblia y la tradición sin restricciones de tipo dogmático (...) 0 como programa de un cristianismo racional y práctico” (Hodgson, 2007, p. 105) el que está presente. En su obra posterior, Bloch (1968a) criticará la tendencia a una reducción liberal de la teología bíblica a una simple ecdótica que despoja la creencia de su contenido revolucionario y vuelve superflua una interpretación de la religión en sentido filosófico. 
un ateísmo vulgar que nos despojase de todo vestigio de interioridad, sino más bien la creación de una especie de religión nueva en donde esos sentimientos profundos continuasen hallando expresión y cauce. Tras un despertar de la conciencia de la humanidad, la pretensión de existencia real del Dios personal y trascendente parecía haberse vuelto definitivamente superflua y se le había, por lo mismo, allanado el camino al ateísmo. No pudieron, sin embargo, apagarse los sentimientos religiosos o, dicho de otro modo, la espiritualidad que dimana de ellos. Para Bloch, lo auténticamente humano y, por eso también, el horizonte insuperable de la religión, los tesoros que ella porta y que ni la polilla ni el orín corrompen, son los sueños de una vida y de un mundo mejores. Al menos en la sustancia de la religión judeocristiana, el creyente, por esencia, lejos de aceptar la tiranía de la realidad y de su orden pretendidamente eterno, entiende lo real como algo transformable. Si el mundo suspira por un apocalipsis que descubra su propio rostro, esto solo puede significar que la realidad no es percibida como totalidad cerrada sobre sí misma sino abierta al maius de una verdad que a la vez que germina en ella, la excede como posibilidad. Esta excedencia es lo propio de la utopía, lo que la hace intraducible a las lógicas económicas o mecanicistas (Dinerstein, 2016).

Ahora bien, una vez que el contenido objetivo del concepto Dios ha desaparecido, se hace necesaria para Bloch una reasunción subjetiva e interior de lo que dicho contenido representa. Más aún, puesto que el anhelo religioso no puede hallar su total y satisfactoria realización, ni en la idea de un supramundo por venir, ni en la ilusión de una relación íntima con el ser que lo habita, es posible pensar en una "vida en religión tras la superación del concepto exterior de Dios" (Bloch, 1992, p. 12). La religión blochiana es, pues, una religión atea pero no una reducción mecanicista de lo humano a la materialidad fútil de un universo desangelado. La nueva religión sin Dios conserva entonces lo esencial del impulso religioso, a saber, la afirmación de la vida y la confianza en la superación del mal y en la negatividad del mundo, que destruye el pesimismo en tanto tentación que permanentemente se ofrece al pensamiento.

Es claro que una idea tal se aleja de la identificación automática de la religión a rebajamiento de la dignidad humana a favor de un ideal hipostasiado y de la crítica feuerbachiana y marxista tradicional (Feuerbach, 1995; Marx, 2014). Para Bloch, en cambio, lo auténticamente religioso consiste, al menos en el judeocristianismo, en un "enorme fortalecimiento de la interioridad del hombre" (Bloch, 1968b, p. 71). Esta interioridad, no obstante, deja de ser entendida como relación exclusivamente vertical y binaria entre la criatura y lo divino, para ser entendida más bien como voluntad rebelde que ordena: "no os amoldéis a este eón" (Rm 12,2), pues precisamente ve en el eón presente el gusano de su obsolescencia que lo destina a su superación escatológica definitiva. Para el marxismo paradoxal de Bloch, la negatividad del contemptus mundi que se halla en el corazón de la crítica de la religión en Marx y aun en Feuerbach, se convierte en el elemento mejor del cristianismo. Este desprecio del mundo no tiene por qué posponer automática e ineluctablemente la justicia a un Reino venidero. Tampoco debe ser leído ni como paz con el presente, ni como capitulación frente a lo que no se puede cambiar. 
Se trata más bien de un desprecio "irónico, peligrosamente burlón" en vez de un "simple rapto sobreterrenal" (Bloch, 1983, p. 128). La religión, pues, que ha sido y es muchas veces opio para el pueblo al servir sin cesar el interés de las clases dominantes, contiene en su forma constitutiva un elemento que no representa una orientación definida y se presta por lo mismo tanto a la reacción como a la emancipación del mundo. Por eso, Bloch (2007) no dudará en afirmar que hay religiones que no son opio para el pueblo, sino más bien acicate de su propia liberación.

\section{El motivo de la Iglesia invisible}

Pero la idea de nueva religión de Bloch no se queda en el rango de simple postulado. Al contrario, es necesario que la idea de nueva religión se efectúe en una forma política concreta, que se transforme en lucha real contra la situación percibida como ruinosa. El itinerario conceptual aquí es análogo al seguido por Kant (1981): en primer lugar, la religión históricamente constituida está llamada a tornarse, para el de Könisberg, en una religión de la pura razón, si bien por ahora esta se halla envuelta bajo la corteza actual de una institución humana. Esta fe racional constituye el corazón no perecedero de la experiencia religiosa, allende los modos contingentes de su expresión histórica. También para Bloch, como hemos mostrado, tras la representación fabuladora de los dogmas, yace un contenido auténtico: el oro escondido bajo el mito. Lo que Bloch nos exige en todo caso, para seguir el hilo de su argumentación, es sin duda que aceptemos con él que el teísmo no hace parte de la sustancia permanente de la religión, y en particular del judeo-cristianismo, sino que es apenas un modo de expresión histórico allende el cual podemos encontrar el centro neurálgico de la fe, a saber, el anhelo, la esperanza convertida en principio que obra. El punto de divergencia está, a nuestro juicio, en el ápex focal del movimiento teórico de los dos filósofos: en este sentido, tal como lo demostró O. Reboul (1970, p. 138), la religión de la razón que Kant propone no es una religión que tendría su fuente en la razón como surtidor yuso de donde saldrían sus contenidos, sino que la razón aparece más bien como su destinación final, puesto que su origen está puesto suso, en el legislador divino. Para Bloch, en cambio, se trata más bien de un impulso que sale de abajo, de la inmanencia misma, y se dirige arriba, hacia lo divino como encuentro con la esencia todavía no revelada de nuestro propio rostro: el homo absconditus.

En segundo lugar, la religión de la razón kantiana tiende a encontrar en una comunidad ética el cauce de su propia constitución. Se trata, como escribe Kant (1981), de "una iglesia, que, en cuanto que no es ningún objeto de una experiencia posible, se llama iglesia invisible, una mera idea de la unión de todos los hombres rectos bajo el gobierno divino inmediato" (p. 101). Es invisible no porque subsista en un más allá que escape a toda determinación del conocimiento sino porque no se constituye ni como institucionalidad fáctica ni como realidad paralela al Estado. Se trata, más bien, de 
una comunidad cuyo topos está en un lugar no-lugar: "idea elevada, nunca plenamente alcanzable" (Kant, 1981, p. 101), en últimas, utopía. Ahora bien, esta palabra hemos de entenderla aquí no como quimera irrealizable o región de la imaginación que espera pasivamente su cumplimiento, sino como kairós que, desde dentro, agarrota y sacude el movimiento de lo real, en tanto que su propia y permanente búsqueda de la producción inmanente del novum.

También Bloch retoma, en varias ocasiones, sobre todo durante sus primeros escritos, la expresión "Iglesia invisible". En el breve texto de 1905, Pensamientos sobre las cosas religiosas (Gedanken über religiöse Dinge), por ejemplo, esta noción se encuentra relacionada en un sentido claramente kantiano con una forma de culto interior propio de la religión atea que él propone. La Iglesia invisible es, por tanto, una comunidad fraterna más allá de la polis como forma social que tiene por organizador al Estado. Por esta misma razón, su verdadera realización sólo puede lograrse plenamente en la sociedad futura, aunque desde ya esta excita la lucha revolucionaria y le sirve de focus imaginarius.

Es la fraternidad universal como ideal eclesiástico por excelencia lo que viene puesto en primer lugar a la hora de la escogencia del término "Iglesia". De modo que, si para el joven Bloch podemos permitirnos hablar de una forma política de la sociedad futura, solo podemos hablar de ella como "una Iglesia necesaria y a priori establecida después del socialismo y orientada hacia el contenido de la Revelación" (Bloch, 1964, p. 306). Esto significa que la cohesión de esta communità che viene no se origina afuera, o arriba, sino que, al contrario, produce en sí misma una concordia general de las almas. La Iglesia invisible es pues una sociedad mística que realiza la democracia pues se entrega a la búsqueda del sí, al desarrollo de las potencialidades personales y a la producción de un sentido de la vida en su devenir total. Esta forma social utópica, esto es, en trance de realización y deseable, tiene como condición previa el fin de la miseria y de la sociedad de clases para que la contradicción exterior de la sociedad capitalista se convierta al fin en contradicción interior productora de un nosotros nuevo. Como lo ha visto bien C. Romagnoli (2008), no se trata de una simple teologización de la política sino de su orientación decididamente apocalíptica, según la cual la activación urgente de las luchas emancipatorias es el único principio capaz de acelerar la historia.

Pero se hace necesario ir más allá. Por fuera de la cáscara religiosa y del tono sibilino bajo el cual se expresa esta doctrina de la Iglesia invisible en la obra juvenil de Bloch, nos parece fundamental resituar su evolución y desarrollo incluso si esta idea se dirige hacia el propósito de una filosofía crítica. Sabemos que la expresión "Iglesia invisible" hace referencia a un concepto eminentemente teológico cuyo origen se remonta a las acerbas disputas entre Agustín y los donatistas y que adquirió luego una importancia capital en la eclesiología de los reformadores. Según esta doctrina, la iglesia de Cristo no coincide con los límites ni espaciales ni temporales de ninguna institución constituida de iure, sino que más bien, corresponde a una realidad mística, interior, presente y actuante por decirlo así en las distintas confesiones, que la expresan 
en mayor o menor grado. Esta iglesia puede ser llamada invisible porque en tanto que "comunidad espiritual", como dice Paul Tillich (1991), "no es un grupo que exista junto a otros grupos, sino que es más bien un poder y una estructura inherente y eficaz en ciertos grupos, es decir, en las comunidades religiosas" (p. 179).

Ya en la Edad Moderna, Kant presentó, como hemos visto, esta Iglesia invisible como una república moral formada por aquellos a quienes el culto a Dios tiende a hacerlos éticamente mejores. Dicha comunidad, más allá de toda fascinación por el poder, aunque con el poder político establece relaciones bajo el principio de la libertad propio de los estados libres, también está fuera de la ley, en una forma política que aún no nos ha sido dada pero cuyo advenimiento presentimos. Su propia época es así, para Kant, ante todo la de un cambio, una salida de la minoría de edad, el tránsito hacia una era de paz que encuentra, en los acontecimientos del propio tiempo, el "signum prognosticum" (Kant, 2003, p. 159) que anticipa la instauración de un reino moral bajo la égida superior de la razón. A principios del siglo XX, Georg Lukács (2013), el amigo por excelencia de Bloch durante su juventud, se expresaba en los siguientes términos acerca del siglo de Kant y del romanticismo:

Hoy llamaríamos probablemente cultura a aquello a lo que aspiraban, pero ellos, como le tenían por vez primera como la meta salvadora y posible ante sus ojos, tenían mil formas poéticas para describirlo y veían mil caminos para acercarse a ello. Sabían que cada uno de sus caminos tenían que llevar a ello; sentían que había que asimilar todo lo pensable, vivir todo lo que se puede vivir, para que la "Iglesia invisible" construir la cual era su misión, fuera toda riqueza y lo abarcara todo. Pareció como si fuera a nacer una nueva religión, una religión panteísta, monista, divinizadora de la evolución, procedente de las nuevas verdades y los nuevos descubrimientos de las nuevas ciencias de la naturaleza (Lukács, 2013, p. 99).

El diagnóstico resulta revelador: Lukács pone la expresión "Iglesia invisible" al interior de una dinámica de búsqueda de un lenguaje performativo que diera cuenta de una nueva manera de vivir que se abría paso en el siglo XVIII. Antes que la simple secularización filosófica de un viejo concepto cristiano reformado, el tránsito hacia algo distinto - la sociedad burguesa que se estaba forjando- se expresaba como nostalgia Sturm und Drang, en un momento en que la conciencia de la nueva época no se encontraba del todo delineada. La nueva religión terminó emparentada en el siglo XIX con la formación de un espíritu nacional y la forja de una tradición intelectual propia en el momento en que, tanto el modo de producción como la racionalización creciente de todos los niveles de la vida, amenazaban la individualidad y se entregaban a la producción en serie de objetos.

En este orden de ideas, a Bloch le interesaba poner de relieve cómo la acción política emancipadora, necesaria para la renovación del pensamiento y de la sociedad alemana con la que el joven estudiante soñaba, está siempre impulsada por la convicción de una profundización de la interioridad del sujeto. Dicho de otro modo, para nuestro 
autor, el acto a la base del cual se asienta toda decisión que tira la realidad hacia su realidad última, está hecho, en el fondo, de una inexplicable libertad, relativamente independiente de causas mecánicas, que consiste en volverse consciente del poder del individuo en particular y, por el mismo camino, del colectivo en general. Este florecimiento de la interioridad está a la base de la convicción de los actores en la posibilidad de un cambio profundo de las estructuras que gobiernan las relaciones entre los seres humanos. La idea de la Iglesia invisible insiste, por tanto, en la necesaria transición utópica entre sociedad y comunidad, como una nueva forma de relación interhumana y deja vislumbrar la posibilidad de una alianza nueva con la naturaleza.

Es la fuerza mágica de esta apoteosis de la interioridad, la que hace finalmente caer las mediaciones sacramentales y/o estatales. Es la eflorescencia del sentimiento del valor del alma misma, lo que configura cualquier auténtico proceso emancipatorio. Tal es para nosotros el significado de "fe sin Dios", que es al mismo tiempo apuesta, optimista pero no ingenua, en un mundo y una vida mejor en tanto que posibles y realizables. Tal deseo, tal búsqueda "es la posesión común de las religiones superiores, es el culto interior como la religión de la Iglesia invisible" (Bloch, 1992, p. 13). Este valor del individuo, del que la Edad Moderna se ha vuelto particularmente consciente, debe ser llevado a una solución definitiva que Bloch seguramente intentará encontrar, en su filosofía de la madurez, en el marxismo. Este se presentará para él como el pensamiento regido por el imperativo moral que exige, según la expresión de la Introducción a la crítica de la filosofía del Derecho de Hegel, "derrocar todas las relaciones en las que el hombre es un ser humillado, esclavizado, abandonado, despreciable" (Bloch, 2007, p. 487).

Casi diez años después de Pensamientos sobre las cosas religiosas, en los textos escritos por Bloch durante la Primera Guerra Mundial y recogidos más tarde en el volumen Lucha sí, guerra no (Kampf, nicht Krieg) aparecen nuevamente las nociones de iglesia en general y de Iglesia invisible en particular. Allí, ante la catastrófica situación a la que la guerra había conducido al pueblo alemán, Bloch aboga por una derrota militar del Reich que pueda humillar las pretensiones militaristas del chovinismo prusiano. Solo la amarga hiel de esta derrota abriría, para nuestro autor, la puerta a la instauración de una república democrática que vuelva menos odiosa la Alemania del furor teutonicus ante el resto de los pueblos del mundo. La situación ruinosa solo podía ser llevada a su fin por una victoria de los aliados que no prolongara más el sufrimiento y la muerte a la que los junkers - la rancia aristocracia conservadora- habían conducido al pueblo alemán. Ahora bien, es en la fina distinción que Bloch establece entre lucha y guerra donde sale a relucir el corazón de su idea: a la violencia de la guerra como política de los estados, viene contrapuesta la noción de lucha. A la primera, corresponde la extrema violencia de los ejércitos y en particular del prusiano. Esta exige una identificación subjetiva con una institución plenamente existente de modo externo (una determinada monarquía, por ej.). La segunda, la lucha, tiene por el contrario un objetivo que no existe más que como ideal colectivo todavía no realizado. En el caso concreto de la guerra, se trata de un pacifismo tanto radical como paradoxal puesto que combativo. Esta lucha contra la 
guerra, que es en el fondo lucha por cuanto hay de humano y bueno, adquiere según Bloch (1985) la forma política de una "ecclesia militans" (p. 486). Dicha iglesia militante es aquí también iglesia purgante que sufre a su vez por dar a luz una realidad nueva:

Solo entonces, y no un momento antes, tras haber vivido y conducido al fin su existencia política, la exigencia de la moral político-social, podrán los alemanes regodearse en las preocupaciones y problemas propios de su existencia inteligible, de la salvación de su "alma sola", de la pertenencia de su ser suprasocial, personal y espiritual, a la "Iglesia invisible" (Bloch, 1985, p. 524).

Nos encontramos de nuevo ante el escollo de esos "elementos religiosos difíciles de digerir en su pensamiento" (Jay, 1984, p. 175), que han dificultado sin duda la recepción de la obra de Bloch para el lector hodierno. Sin embargo, detrás de esta cáscara evocadora, podemos al menos identificar tres elementos: (1) en primer lugar, el espíritu völkisch de principios del siglo XX (Pelletier, 2010), expresión romántica de la búsqueda de una nueva religión nacional que colmara de significado el mundo desencantado que la industrialización había puesto en marcha. El así llamado "völkisch religiöse Bewegung" (movimiento religioso popular) si bien es identificado como una corriente antisemita y conservadora, también puso la religión en el debate académico a través de una forma particular de crítica social que lamentaba la pérdida de valores nacionales en favor de un materialismo traído por la creciente urbanización y la industrialización acelerada. Uwe Puschner (2017) sugiere en este sentido que, a nivel religioso, este movimiento se expresó sobre todo o como afirmación del carácter particular del cristianismo alemán o como vuelta al paganismo precristiano. Beat Dietschy (2018a), por su parte aclara que, aunque con el nacionalsocialismo nociones como "comunidad popular" (Volkgemeinschaft) adquirieron más tarde un carácter evidentemente racista y agresivo, a principios del siglo XX, el movimiento völkisch era todavía ambiguo en sus manifestaciones y tendía, a veces, a revalorizar simplemente lo popular, incluso solapando conflictos de clase. Ahora bien, en el pensamiento de Bloch, ese "motivo völkisch" se expresa en la obra de juventud como voluntad de realizar una síntesis nueva entre judaísmo y alemanidad. Esta reapropiación particular del movimiento conduce a nuestro autor al uso intensivo de un lenguaje esotérico, muy en boga en los autores judíos de la época. Si retomamos la intuición de Anson Rabinbach (1985) esta apuesta no consiste solamente en el uso de un género literario particular, sino en una opción consciente que buscaba poner de manifiesto, tanto la incomodidad que dicha generación sentía frente la filosofía heredada de la Ilustración como su predilección por el lenguaje apocalíptico de los antiguos profetas debido a su poder evocativo.

(2). En segundo lugar, hemos de ver en este regreso a la idea de iglesia, en el contexto de la Primera Guerra Mundial y de la filosofía de la juventud de Bloch en general, la búsqueda apasionada de un referente que venciera la desilusión experimentada ante una Alemania sin brillo, donde "la juventud tenía que perecer, condenada a 
muerte (...) mientras que los desdichados estaban fuera de peligro, asentados en un lugar cálido" (Bloch, 1964, p. 11); un país donde incluso la sal se había vuelto sosa y sus universidades, por ejemplo, se habían convertido en "verdaderos cementerios de la mente, el eje (protofascista, A.P.C.) de un "despertar de Alemania", infectados por la inmovilidad, la pereza y el oscurantismo" (Bloch: 1964, p. 294). Es, pues, lo alemán lo que está en juego y debe ser despertado por medio de un retorno a la tradición religiosa pues "no se conoce cultura alemana sin la Biblia (...). Esta cultura es justamente la que lleva interiorizada la Biblia y se extiende desde Eckhart hasta el propio Mahler" (Bloch, 2019, p. 63).

(3). La Iglesia invisible aparece claramente referida a un momento de renovación cultural que debía poner fin al periodo sombrío que estaba en curso: como la época de la entrada de Alemania al capitalismo mundial que concluyó con la Gran Guerra y preparó catástrofes posteriores. Se trata para Bloch de la realización real del ser político que se produce a condición de que el ser humano sea liberado del desasosiego en el que vive por cuenta de lo que no es esencial. Por eso, en El espíritu de la utopía, el socialismo es presentado como la supresión de la miseria y de la sociedad de clases (momento negativo) que dará lugar al momento positivo, a saber, "devolver a cada uno, más allá del trabajo, su propia miseria, su hastío, sus propias sombras, su luz traslapada" (Bloch, 1964, p. 333). Aquí esta especie particular de religiosidad quiliástica de Bloch, en alianza con un comunismo político a su manera, encuentran su base, como afirmó en su momento S. Kracauer (1990), en la relación más profunda entre "el sufrimiento tosco que viene de afuera y el sufrimiento auténtico que viene de adentro" (p. 461). Esa organización de lo fundamental es el socialismo que se edifica, pues, como iglesia en donde los sujetos, liberados del yugo de la búsqueda de la superviviencia, se entregan a la construcción y a la búsqueda de sí mismos. Para realizar por tanto el encuentro con el propio rostro descubierto (que constituye el sufrimiento auténtico) y rasgar el velo del secreto metafísico de lo que somos capaces como humanidad, es necesario que dejemos de vivir por el solo pan (que representa al sufrimiento "tosco"). Esa es

la Iglesia instaurada tras el socialismo que pone sus miras en el contenido nuevo de la Revelación (...). Iglesia que se halla en la vida allende el trabajo (...). Entonces la humanidad libre podrá ocuparse de esos asuntos prácticos que nos asaltan al momento de la muerte, tras una vida que consistió en encubrir lo fundamental (Bloch: 1964, p. 307).

Queda claro que la iglesia es apenas un nombre performativo que sirve para indicar el espacio de lo anti-banal que define para Bloch la esencia misma de lo religioso. Hay, pues, religión no solo allí donde existe la creencia en un ser espiritual que trasciende el mundo, sino sobre todo allí donde hay profundidad, allí donde el ser humano se ha vuelto homo intensivus y se ocupa y se agita no por las muchas cosas sino por el unum necessarium, la parte mejor que a nadie le será quitada. Lo que ha sido designado como Dios, pues, no es más que otra manera de decir "vida suprema, objeto del deseo 
supremo" (Bloch, 2007, p. 290), que no desaparece ni siquiera cuando su contenido ontológico extramundano deja de significar.

"La iglesia formativa -escribe Bloch en Thomas Münzer, teólogo de la revolución-, la que todavía es visible a los ojos terrenales, se halla localizada en el horizonte entre este mundo y el más allá; en el otro mundo, bajo la forma totalmente desconocida de la Iglesia invisible" (1968b, p. 204). Por iglesia formativa, se refiere el autor sobre todo a la expresión social del catolicismo en situación cultural dominante, como fue el caso por ejemplo en la Europa de la Edad Media, cuyos remanentes seguían vivos tras la Reforma. La institución eclesiástica estaba llamada a servir en ese contexto de pasarela del Reino. Pero, como ha recordado B. Dietschy (2018b), el futuro utópico no brilla únicamente para Bloch al final del camino de la historia, sino que también despunta en el pasado, en momentos como el de la guerra revolucionaria de los campesinos alemanes del siglo XVI y en el grito de batalla de Münzer: "omnia sunt communia". Bloch mismo afirma, en un texto de 1920, recogido en los Ensayos filosóficos, que el pathos quiliástico de la lucha campesina realizó el sueño de la Iglesia invisible en tanto que "comunidad supraeconómica, suprapolítica, emancipada de toda esfera económica, administrativa y gubernamental" (Bloch, 1969, p. 206). Así pues, esa construcción religiosa enteramente futura, pero de algún modo presente ahora de modo misterioso, constituye en últimas el contenido común de todas las utopías sociales, el "tema universal de la historia" (Bloch, 1969, p. 210). Bloch dejará entender, en este sentido, que el anhelo religioso pinta de fantasía lo que el marxismo describe de modo científico: la posibilidad de una resolución de la contradicción económica para encontrar, según Bloch, la contradicción fundamental que solo trae el encuentro consigo mismo. Ciertamente, para nuestro autor, "[l]a existencia de Dios, incluso Dios como esencia propia, es una superstición" (2007, p. 312); en cambio, "[l]a verdad del ideal de Dios consiste únicamente en la utopía del reino, y la presuposición de esta es que no quede ningún Dios en las alturas, allí donde, por lo demás, ni lo hay ni nunca lo hubo" (Bloch, 2007, p. 414).

Así pues, tanto el motivo de la Iglesia invisible de la filosofía de la juventud, como el motivo del Reino presente en El principio esperanza, nos ponen ante lo que Michaël Löwy (2009) considera una disolución teocrática y anarco-romántica de la religión y de la idea de Dios. Tanto en el Reino como en la Iglesia invisible, en efecto, la característica principal es la ausencia de mediación. Según el esquema kantiano, en la Iglesia invisible cada miembro recibe órdenes directamente del legislador supremo. En la idea blochiana, lo que se produce más bien es la ausencia de una institución dispensadora de los misterios. El Reino, para el cual y por el cual la iglesia existe como comunidad militante en el mundo, hace superflua a la misma iglesia cuando este se realice plenamente. Por eso, si la iglesia existe para engendrar el Reino y enseguida desaparecer su vocación en tanto que institución es el suicidio. Siendo Dios "todo en todos" (1 Co 15, 28) en el Reino, el centro del poder deja de estar concentrado en una instancia análoga al Estado para redistribuirse en una interioridad que alcanza su 
punto de mayor intensidad en la comunidad que hace por lo mismo explotar el poder para dar paso a una democracia mística (Ver Pineda Canabal, 2015). En este sentido, el anabaptismo de Münzer, al negar el carácter sacramental que, en la teología católica, imprime el baño bautismal y al exigir un nuevo rito por inmersión a sus adeptos, devalúa por la misma razón la forma cultual-estatal de la iglesia. Viene así acentuada "la libertad de asociación, el carácter internacional de los pobres de espíritu, de los elegidos, por encima de los Estados, el nihilismo respecto de las leyes establecidas y el libre desempeño de la moralidad elegida y comprendida" (Bloch, 1968b, p. 102). El debilitamiento de la forma jurídica positiva trae pues consigo un tipo de unión que el sintagma "Iglesia invisible" subraya y que, llevado a sus más radicales consecuencias políticas, significaría "una existencia sin propiedad, sin Estado, sin Derecho coactivo" (Bloch, 1980, p. 32) como el único camino de realización de una existencia cristiana, es decir, plenamente libre, que no puede darse de modo exclusivamente individual y presupone un nosotros.

\section{Religión y anticapitalismo: a modo de conclusión}

En resumen, Bloch usó pocas veces la expresión "Iglesia invisible" y, por lo general, lo hizo en sus escritos de juventud. Después de los años veinte, la expresión tiende a desaparecer de su obra mientras que su interés se concentra en la elaboración de una especie de teoría metarreligiosa donde incluso la intención juvenil de una religión sin Dios, constituida como iglesia, es abandonada. Para el proyecto filosófico de su madurez, la religión tiene todavía por objetivo el mantenimiento y desarrollo de una conciencia de la necesidad utópica. Es decir que, aunque sigue siendo un antídoto contra la trivialidad y el nihilismo (en el sentido de los primeros escritos), es ante todo presentada como incitación y llamada a una existencia plena en la que todos reencuentren las "fuentes del coraje de vivir" (Bloch, 1968a, p. 222). Ahora bien, en esta expresión madura de sus

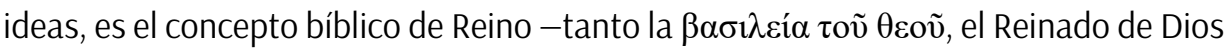
del Nuevo Testamento, como el postulado moral del reino de la libertad de Marx- el que adquiere para Bloch un papel primordial y reemplaza el motivo juvenil de la Iglesia invisible. Pero lo decisivo es que dicho itinerario se inscribe al interior de una apuesta decidida por un materialismo especulativo que busca encontrar la trascendencia al interior de la inmanencia de la materia misma, en tanto que esta es productora de nuevas determinaciones y saltos en los que se inscribe la totalidad de la obra de la emancipación humana.

En este proyecto de metarreligión, aunque la expresión "Iglesia invisible" está ausente, el concepto de iglesia en general cumple todavía una función heurística. Así, en Derecho natural y dignidad humana, publicado en 1961, Bloch, al considerar el sueño internacionalista de una ecúmene comunista, entiende este según el paradigma eclesiástico clásico al modo en que aparece, según lo expuesto, en El espíritu de la 
utopía. Es así como el postulado de una nueva alianza interhumana que implica la superación de la explotación del hombre por el hombre le hace poner a nuestro autor, allende la potencia-Estado pasajera, una potencia-iglesia duradera, como "una administración del sentido; algo que ordena los ánimos e instruye los espíritus" (Bloch, 1980, p. 280). Si es cierto pues que no solo de pan vive el hombre, la emancipación verdadera deberá consistir entonces en la liberación de la carga, tantas veces apabullante y grosera, de la búsqueda del propio sustento en la que se desperdicia lo mejor de nuestras fuerzas. Lo que se ofrece en cambio, no es una utopía del ocio sino una recuperación auténtica del trabajo humano en la que, no viviendo ya solo por el pan, aparezcan al fin preocupaciones dignas de ser consideradas específicamente nuestras: "las preguntas acerca de la meta, acerca del hacia dónde y el para qué" (die Zielfragen des Wohin und Wozu) (Bloch, 1980, p. 280, traducción modificada). Tal es la realización de la "necesidad metafísica" (metaphysische Bedürfnis, wirklich metaphysische Frage, Bloch insiste en ello cambiando a veces los términos [1980, p. 281]) de la existencia propiamente humana.

Pero, sucede a veces que los árboles no nos dejan ver el bosque. Algo parecido ocurre con el lenguaje blochiano que, tan cargado de patetismo, llega a disimular sus verdaderos objetivos. Ya Kracauer (1990) temió, en su momento, que el retorno a lo religioso que se evidenciaba desde distintos frentes en la intelligentsia judía de la época, terminara siendo a la postre un proyecto reaccionario desligado de la realidad. Con él es acaso posible negarse al falso dilema en el que Bloch nos pone, a saber, la necesidad de decidir entre una razón capitalista, abstracta, descolorida y sin vida, por un lado, y una recuperación romántica y para algunos retrógrada del entusiasmo religioso, por el otro. Kracauer mismo (Bloch, 1985) propuso una tercera vía en vista de una teoría propiamente revolucionaria: "que los remanentes ocultos de verdad que fueron encontrados por el lenguaje teológico (...) sean arrancados de sus envolturas mitológicas y puestos en su lugar actual" (p. 274). Dicho lugar correspondería al interior de una filosofía de la historia llamada a realizar un proceso de desmitologización de dichas categorías. Aquel "migrar y transformar" (Wanderung und Wandlung) que proponía Kracauer (Bloch, 1985, p. 274) significa hoy para nosotros el reconocimiento de una intención eminentemente crítica en las ideas de Bloch, que nos corresponde desentrañar.

"Tout va bien, dicen muchas apariencias, como si esa convención no fuera desconocida por las cosas" (Bloch, 2005, p. 148): se trata de una especie de inercia inherente al curso histórico, una resistencia fatalista de las cosas mismas a cambiar. En esto radica la dificultad de explicar los saltos revolucionarios y la decisión que origina la libertad. En este orden de ideas, una explicación de naturaleza económica y simplemente materialista no sería suficiente para explicar el origen de la obra de la emancipación humana. Por eso, gran parte de la filosofía de Bloch gira en torno a la necesidad de reconocer una "relativa libertad de los factores subjetivos" (Bloch, 1965, p. 449) al interior de la historia. 
"[L]a pobreza en sí no tiene nada de subversivo" (Bloch, 2005, p. 34) ni el hambre produce revoluciones espontáneas sino, a lo sumo, saqueos y conatos de reyerta. Así pues, la rabia suele detenerse en el bar, en el estadio, en la vitrina, o en el más débil. Luego se ahoga, sin llegar a ser transformadora. El impulso de la emancipación, en cambio, suele ser misterioso e íntimo y prueba con creces que el apetito económico no constituye ni el más constate ni el más fuerte de los apetitos, ni tampoco la más auténtica de las pulsiones humanas. Por supuesto que las condiciones socio-económicas representan un desafío fundamental a la hora de levantar el puño izquierdo. El acto revolucionario no es solo interior, sino que halla su combustible en los momentos en que la concentración de las contradicciones del sistema llega a su punto máximo. Pero esto no es suficiente para explicar el resto: hay sueños que "no proceden de un estómago vacío" (Bloch, 2019, p. 111). Por debajo, un agua de utopía corre secretamente; detalle olvidado acaso por el marxismo y por el positivismo moderno: el sueño de algo que se busca y que insurge dondequiera siempre con matices distintos. Por eso Bloch (1968b) afirma hablando de la Guerra de los Campesinos alemanes:

[S]e ha de considerar, además de los elementos del desencadenamiento y del contenido del conflicto, todos ellos de orden económico, el elemento esencial originario en sí mismo, a saber, en cuanto retorno del más antiguo ensueño, en cuanto más ancho estallido de la historia de las herejías, en cuanto éxtasis del caminar erguido y de la impaciente, rebelde y severa voluntad de paraíso. Las aficiones, los sueños, las emociones serias y puras y los entusiasmos proyectados hacia un fin no se sustentan de la necesidad más tangible, y pese a ello, jamás son ideología vana; no decaen, sino que contribuyen a dar un color de realidad a un largo período, provenientes de un punto original, creador y determinador de valores, que hay en el alma, y siguen ardiendo, inextinguibles, aun después de toda catástrofe empírica (p. 67).

En eso reside la clave del interés blochiano por la religión: en que, si bien esta es superstición de un lado, también es rebelión del otro, expresión privilegiada de la dimensión utópica que constituye un "aspecto esencial de la condición humana" (Mondragón González, 2005, p. 55). Lo que se realiza en el alma por medio de la fe viene a esclarecer así de algún modo el impulso primero del acto emancipador. Para entender esto, Bloch no intenta inventar nuevas fórmulas, sino que más bien toma símbolos anclados en la memoria cultural del Occidente cristiano, cuya fuerza sugestiva no se asocia de manera puramente intelectual a ningún significado que pueda ser difícil de reconocer de inmediato. Este vocabulario cristiano para él era capaz de despertar una conciencia común, probablemente dormida, pero altamente performativa.

La necesidad de un nuevo lenguaje, de una nueva filosofía, de un nuevo sentido, toma la forma de un anticapitalismo expresionista que parece suspirar por herramientas teóricas más completas que serán desarrolladas en su filosofía posterior, en parte 
gracias al marxismo. Esta inquietud religiosa que despunta desde los primeros escritos, atraviesa la obra entera de Bloch. Él es, como dice A. Münster (1984)

probablemente el único filósofo que haya logrado realizar, en su rica obra de veinte grandes tomos, una síntesis entre (...) la metafísica de la religión judía y las corrientes heréticas del cristianismo con la visión del mundo del expresionismo y la antropología marxiana (p. 109).

\section{Referencias}

Baur, F. C. (1867). Lehrbuch der christlichen Dogmengeschichte. Fues: Leipzig.

Bloch, E. (1909). Kritische Erörterung über Rickert, und das Problem der Erkenntnistheorie. Ludwigshafen am Rhein: Baur.

Bloch, E. (1923). Durch die Wüste, Kritische Essays. Berlin: Paul Cassirer.

Bloch, E. (1964). Geist der Utopie, Bearbeitete Neuauflage der zweiten Fassung von 1923. Frankfurt am Main: Suhrkamp.

Bloch, E. (1965). Literarische Aufsätze. Frankfurt am Main: Suhrkamp.

Bloch, E. (1968a). El ateísmo en el cristianismo, La religión del éxodo y del Rein (J. A. Gimbernat Ordeig, Trad.). Madrid: Taurus.

Bloch, E. (1968b). Thomas Münzer, teólogo de la revolución (J. Deike Robles, Trad.). Madrid: Ciencia Nueva.

Bloch, E. (1969). Philosophische Aufsätze zur objektiven Phantasie. Frankfurt am Main: Suhrkamp. Bloch, E. (1980). Derecho natural y dignidad humana (F. González Vicén, Trad.). Madrid: Aguilar. Bloch, E. (1985a). Briefe 1903-1975, tomo 1. Frankfurt am Main: Suhrkamp.

Bloch, E. (1985b). Kampf, nicht Krieg, Politische Schriften 1917-1919. Frankfurt am Main: Suhrkamp. Bloch, E. (1992). Gedanken über religiöse Dinge (1905). Ernst Bloch Almanach, 12, 9-13.

Bloch, E. (2004). El principio esperanza, tomo 1 (F. González Vicén, Trad.). Madrid: Trotta.

Bloch, E. (2005). Huellas (M. Salmerón Infante, Trad.). Madrid: Tecnos.

Bloch, E. (2007). El principio esperanza, tomo 3 (F. González Vicén, Trad.). Madrid: Trotta.

Bloch, E. (2019). Herencia de esta época (M. Salmerón Infante, Trad.). Madrid: Tecnos.

Dietschy, B. (2018a). Im Mischdunkel nationaler Berauschung. Ernst Blochs Erbschaft dieser Zeit, in Zeiten des Rechtspopulismus gelesen. Das Argument, 325, 31-44.

Dietschy, B. (2018b). Ernst Bloch, Thomas Müntzer y la memoria liberadora de la espiritualidad del "Hombre Común". Actas Teológicas y Filosóficas, 23, 23-39.

Dinerstein, A. (2016). Organizando la esperanza: utopías concretas pluriversales contra y más allá de la forma valor. Educação \& Sociedade, 37 (135), 351-369. https://doi.org/10.1590/ES0101-73302016162414 
Feuerbach, L. (1995). La esencia del cristianismo (J. Iglesias, Trad). Madrid: Trotta.

Harnack, A. (1961). History of Dogma. 7 tomos. (N. Buchanan, Trad.). New York: Dover.

Hodgson, P. (2007). Liberal Theology. A Radical Vision. Mineápolis: Fortress Press

Jay, M. (1984). Marxism and totality, The adventures of a concept from Lukács to Habermas. Berkeley and Los Angeles: University of California Press.

Kant, I. (1981). La religión dentro de los límites de la mera razón (F. Martínez Marzoa, Trad.). Madrid: Alianza.

Kant, I. (2003). El conflicto de las facultades (R. Aramayo, Trad.). Madrid: Alianza.

Kracauer, S. (1990). Prophetentum (1922). Schriften, band 5.1. Aufsätze 1915-1926 (pp. 196-204). Frankfurt am Main: Suhrkamp,

Löwy, M. \& Sayre, R. (2009). Esprit de feu, Figures du romantisme anti-capitaliste. Paris: Éditions du Sandre.

Lukács, G. (2013). El alma y las formas (M. Sacristán, Trad.). Valencia: PUV.

Marx, K. (2014). Introducción a la crítica de la filosofía del derecho de Hegel (J. Ripalda, Trad.). Valencia: Pre-textos.

Mondragón González, A. (2005). Ernst Bloch: el peregrino de la esperanza. Estudios políticos (México), 4, 43-77. https://dx.doi.org/10.22201/fcpys.24484903e.2005.4.37642

Münster, A. (1984). Figures de l'utopie dans la pensée d'Ernst Bloch. París: Aubier.

Nietzsche, F. (2007). La Gaya Ciencia (A. Mardomingo, Trad.). Madrid: Edaf.

Pelletier, L. (2010). Ernst Bloch et les juifs ; autour d'une traduction récente. Philosophiques, 37(1), 219-236. https://doi.org/10.7202/039724ar

Pineda Canabal, A. (2015). La noción de democracia mística en «Thomas Müntzer, teólogo de la revolución». Ápeiron. Estudios de filosofía (Edición conmemorativa. LI Congreso Filosofía Joven, Poder y movimientos), 277-291.

Puschner, U. (2017). The völkisch-religiöse Bewegung in the long fin de siècle and National Socialism. Kirchliche Zeitgeschichte, 30(1), 162-174. https://doi.org/10.13109/kize.2017.30.1.162

Rabinbach, A. (1985). Between Enlightenment and Apocalypse: Benjamin, Bloch and Modern German Jewish Messianism. New German Critique, 34, 78-124. https://doi.org/10.2307/488340

Reboul, O. (1970). Kant et la religion. Revue d'histoire et de philosophie religieuses, 50(2), 137-154. https://doi.org/10.3406/rhpr.1970.4010

Romagnoli, C. (2008). Ernst Bloch e la teologia politica. Prassi, mito ed escatologia. Europa e Messia. Paure e speranze del XX secolo in eredità, B@belonline/print, 4.

Tillich, P. (1991). Théologie systématique 4. La vie et l'Esprit (J.-M. Saint, Trad.). Genève: Labor et Fides. 